\title{
Analyst extraversion: characteristics and career outcomes
}

\author{
Patrick Kielty \\ Fisher College of Business \\ The Ohio State University \\ (614) 292-6547 (office) \\ kielty.6@osu.edu \\ Marcus Kirk \\ Fisher School of Accounting \\ University of Florida \\ (352) 273-0222 (office) \\ marcuskirk@ufl.edu \\ Diana Weng \\ Fisher School of Accounting \\ University of Florida \\ (352) 273-0227 (office) \\ diana.weng@warrington.ufl.edu
}

November 2019

\section{Preliminary - please do not cite or circulate}

We thank Andy Call, Scott Emett, Lucile Faurel, Eddue Fuste, Artur Hugon, Eldar Maksymov, and workshop participants at Arizona State University, 2019 Florida Accounting Symposium, and the 2018 Graduate Research in Accounting Conference (GRACE) at Emory for helpful comments and suggestions. Thank you to Johnathan Urbine for his assistance with the conference call transcripts. 


\title{
Analyst extraversion: characteristics and career outcomes
}

\begin{abstract}
ABSTRACT: This study investigates whether sell-side analysts' personality characteristics are associated with job performance and career outcomes. Using well-established statistical linguistic learning techniques, we determine the extraversion level of each analyst. We find that extraverted analysts issue more pessimistic earnings forecasts and less accurate but bolder earnings forecasts. We find that extraverted analysts are less likely to participate on conference calls and, when they do, talk less and have fewer dialogues with management. We also find that extraverted analysts are less likely to be recognized as Institutional Investor All-Stars. Our findings suggest that while prior research finds that extraversion is related to positive outcomes in the executive setting, it is related to more negative outcomes in an analyst setting.
\end{abstract}

Keywords: Analyst information acquisition, Earnings forecasts, Personality

Data availability: Data are publicly available from the sources identified in the paper. 


\section{INTRODUCTION}

An emerging literature in accounting and finance highlights the role of personality traits in financial markets. Recent studies have primarily focused on how the personality attributes of top executives relates to career and firm outcomes; for example, extraversion (Green, Jame and Lock 2018), voice (Mayew and Venkatachalam 2012), and narciscism (Ham, Seybert and Wang 2018). In this paper, we extend this literature and study the influence of personality in the performance and career path of sell-side analysts. Specifically, we investigate the role of extraversion.

Investigating the role of personality within analysts provides relevant insights within the capital market setting. First, it helps acquire a more complete understanding of the career outcomes and incentives of a key capital market intermediary. In contrast to the popular view that analysts spend most of their time on quantitative tasks, a major part of an analyst's time and compensation relates to softer, more qualitative tasks (Bradshaw, Ertimur and O'Brien 2017). Personal attributes potentially play a bigger role in these qualitative tasks, such as communicating with management and institutional clients, broker-hosted conferences, and arranging access to management. Institutional and regulatory shifts since the early 2000s have reshaped the business models of equity research firms to place more emphasis on these types of "high-touch" and "concierge" services (Green, Jame, Markov and Subasi 2014; Maber, Groysberg, and Healy 2014; Drake, Joos, Pacelli, and Twedt 2019). Second, there is limited evidence on the role of personal relationships in financial markets. Brochet, Miller and Srinivasan (2014) find that personal relationships can develop between managers and analysts, and that these relationships are related to an analyst's coverage decision and the characteristics of the forecasts. In this paper, we introduce extraversion to the analyst literature and relate it to the performance and career outcomes of analysts; we also examine the interactions between managers and analysts of different and similar personality types. 
We focus on extraversion as the psychology field has identified extraversion as the most relevant "Big Five" personality characteristic. Extraversion is most directly related to social interaction, correlated with leadership positions, often cited as the most important aspect of an individual's personality, and related to performance and career outcomes within CEOs and CFOs (Cain 2012; Judge et al. 2002; Green et al. 2018).

Our study follows recent research on executives (e.g. Gow, Kaplan, Larcker and Zakolyukina 2016; and Green et al. 2018) to use a computer-based text analysis tool to create an extraversion measure based on linguistic features of analysts and executives within a large sample of quarterly conference calls over 2006 to 2016. We use Seeking Alpha to obtain earnings call transcripts and extract the spoken language of the analyst from the question and answer section of the conference call. We aggregate all of the spoken text from an analyst across all calls to develop our analyst-specific measure of extraversion. After linking the analyst to I/B/E/S, our final sample is comprised of 3,300 unique analysts from the 64 largest brokerage houses over 2006 to 2016 (approximately $75 \%$ of analyst-conference-call observations).

We find that extraverted analysts exhibit significant differences in their public forecasting characteristics. Specifically, extraverted analysts are associated with more pessimistic and less accurate earnings forecasts. While extraverted analysts are related to bolder forecasts that move away from the consensus, they also appear more likely to issue timely forecasts following a firm's earnings announcement. Within the conference call setting, extraversion in analysts is negatively related to conference call participation with extraverted analysts being less likely to participate on the call and, upon participating, have fewer dialogues with management and say fewer words. This is consistent with extraverted analysts being less focused and less able to produce accurate 
forecasts in this environment. A lower number of dialogues with management on the conference call is also consistent with less preparation and follow-up questions.

Our primary summary measure captures the qualitative aspects of an analysts' job and career success. Using it, we find that extraverted analysts are less likely to be voted as Institutional Investor "All-Star" analysts. Ranking lower based on the perceptions of institutional clients suggests that extraverted analysts are less adept at providing the informative, qualitative services valued by institutional investors. Practitioner and academic surveys indicate that pleasing institutional clients is the main determinant of career success for a sell-side analyst even above their public earnings forecasts or recommendations. We use $\mathrm{I} / \mathrm{B} / \mathrm{E} / \mathrm{S}$ to track the analyst within the database to infer the employment history of the analyst (such as promotion, demotion, termination). Using these proxies, we find that extraverted analysts appear less likely to work for a prestigious brokerage, less likely to have a longer tenure at their existing brokerage, and less likely to move up to a prestigious brokerage.

Having examined how analyst extraversion is associated with performance and career outcomes, we next explore the effect of personality similarity/dissimilarity within the analyst/manager relationship. We compare extraverted analysts following extraverted CEOs as well as dissimilar pairs (i.e. extravert-introvert). While Green et al. (2018) find that extraverted CFOs are more likely to be promoted to CEO if the prior CEO was extraverted, we find no evidence that personality similarity within the analyst-executive relationship is related to the forecast characteristics or career outcomes of the analyst.

Our study makes several notable contributions to the accounting and finance literature. First, our paper is the first to examine the personality characteristics of sell-side analysts and how they relate to job performance. Prior studies have analyzed characteristics and inferred traits, such 
as overconfidence, from gender (Kumar 2010; Barber and Odean 2001). Other finance studies have examined the extraversion of firm executives, such as CEOs and CFOs. We are first to examine extraversion in analysts, an important information intermediary. We use a wellestablished method to examine directly how an important personality characteristic, extraversion, relates to an analyst's job performance. Contrary to the executive literature, we find that extraversion is related to poorer performance and worse career outcomes in the analyst setting.

The second contribution is that our study studies the information gathering and evaluating approach of analysts. Analysts create their competitive advantage through "analyzing" information and communicating this information with management and buy-side clients. While the psychology literature may link extraversion to enhanced social skills, extraverted analysts appear less adept at condensing this information into accurate and timely forecasts.

\section{PRIOR RESEARCH AND HYPOTHESES}

\section{The Big Five personality characteristics and extraversion}

The psychology literature uses the term "Big Five" to refer to the five personality characteristics that allow researchers to define one's personality structure (Block 1995). These five characteristics are comprised of neuroticism, openness to experience, agreeableness, conscientiousness, and extraversion. Much of the research around the five personality characteristics centers on leadership ability (Bono and Judge 2004). Psychologists use neuroticism to describe individuals who are characterized by high levels of anxiety and fear and low levels of self-esteem (Judge, Erez, Bono and Thoresen 2002). If an individual scores high for neuroticism, they view the world through a negative lens. Often neuroticism is viewed as orthogonal to extraversion (Rustings and Larsen 1997). Openness to experience is typically correlated with 
creativity and artistic ability (Feist 1998). The third trait, agreeableness, represents individuals who are empathetic, gentle, and trusting, while the absence of agreeableness is a lack of empathy. The fourth personality trait, conscientiousness, is a measure of how aware a person is of their own behavior.

The fifth personality trait and most important to this study is extraversion. Extraversion is most closely tied to social interactions, cited as the most important aspect of an individual's personality, viewed as a more permanent personality trait, and most readily measured through communication style (Dewaele and Furnham 1999, Cain 2012, Judge et al. 2002, Green et al. 2018). Psychologists categorize an extravert as a person who thrives on social stimuli. They are assertive, talkative, energetic and bold (Costa and McCrae 1992; Bono and Judge 2004). They are also opinionated with their ideas (Judge et al. 2002). Extraverts are optimistic people who are most likely found in executive positions; for example, $50 \%$ of the U.S. population is characterized as an extravert, but $96 \%$ of US leaders are extraverts (Ones and Dilchert 2009). Prior literature has shown that extraverts are associated with specific, positive outcomes. The psychology literature has demonstrated that extraverts take on challenges with energy and enthusiasm. Green et al. (2018) find support for this finding in executives of publicly traded firms. They provide evidence that extraversion is associated with significant career outcomes and that extraverted CEOs and CFOs receive significantly larger compensation, especially early in their careers as an executive. Extraversion also has implications for an executive's career, as they are more likely to be promoted to CEO compared to introverted leaders. Lastly, extraverted CEOs are more likely to serve on outside boards and as directors.

The finance literature has also shown the downside of being extraverted. Gow et al. (2016) investigate the Big Five personality characteristics in executives and how those traits affect firm 
performance. They find that extraverted CEOs are associated with negative current and future returns on assets. One potential explanation is that extraverted CEOs are bold and are less willing to take advice or criticism, especially from lower-ranking employees. The psychology literature has found that extraverted executives often make rash decisions about acquisitions and investments. If those investments do not pan out, they are more likely to discontinue those projects (Beaudecel et al. 2006). Cain (2012) shows that being introverted can have its advantages as well. She argues that introverts are more likely to pay attention to smaller details and more capable of reading people's moods.

\section{Extraversion and Analysts}

A disconnect exists between the perception of sell-side analysts as number-driven quants and the importance of communication and relationships to their visible outputs as well as their compensation and career success. Institutional and regulatory shifts since the early 2000s have reshaped the business models of equity research firms to place more emphasis on these types of “high-touch" and "concierge" services (Green et al. 2014; Maber et al. 2014; Drake et al. 2019). Personal attributes potentially have a bigger role to play in these qualitative tasks such as communicating with management and institutional clients, broker-hosted conferences, and arranging access to management.

The primary source of a sell-side analyst's compensation is derived through broker votes. Broker votes are distributed by the buy-side clients and determinate how research commissions are distributed to the brokerages. Thus a primary incentive for sell-side analysts is meeting the specialized needs and managing the relationships with institutional clients. In academic (e.g. Brown, Call, Clement and Sharp 2015, 2016) and practitioner surveys (e.g. the Institutional All- 
Star), institutional investors view relationship management as a primary benefit of sell-side analysts (along with industry knowledge). Institutional clients "hate written product, and would rather spend two hours on the phone with the analyst" (Drake et al. 2019). The analyst's connection with company management is also of major importance. An extravert thrives in social situations and on social connections. Thus, an extraverted analyst is more capable of managing their relationships with non-executives, such as buy-side clients. Bradshaw et al. (2017) provide evidence of this in job postings for associates listing visiting company, attend conferences, and "build and maintain relationships with company executives." Despite this central focus on relationships, there is scant evidence of relationships in capital markets. Brochet et al. (2014) provide the most direct evidence of relationships between analysts and managers.

\section{Predictions}

\section{Extraversion and job performance}

Ex-ante, the directional relationship between analyst extraversion and their job performance and forecast characteristics is unclear. Extraverts have certain advantages in the work field, as established by the psychology literature. Extraverts are characterized by having energy, enthusiasm, and vision for the challenges they face at work. Consistent with their role as information intermediaries within the capital markets, sell-side analysts gather and process information. An information advantage is critical to an analyst's career, as industry knowledge is a main determinant of compensation and is the number one trait valued by institutional investors (Brown et al. 2015; Bradshaw 2011). Senior analysts spend the majority of their time cultivating and communicating with their network of contacts in order to develop this information expertise (Bradshaw et al. 2017). Typically, an analyst will have private phone calls with an executive, either 
the CEO or CFO, at least once per quarter (Soltes 2014; Brown et al. 2015). These private conversations are an opportunity for the analyst to convey what information they need and also receive feedback on their investment thesis (Bradshaw 2011). Extraverts' advantage in social interaction could lead to developing a broader network of contacts with deeper relationships. This informational and relationship advantage is likely to be associated with variables such as more accurate and informative earnings forecasts, and preferential treatment on conference calls.

On the other hand, it is possible that extraverted analysts will underperform compared to introverted analysts. Extraverts are also characterized by a propensity to behave in bold and aggressive ways. For instance, Gow et al. (2016) analyze the association between CEO personality and firm performance. They find that extraverted CEOs are negatively associated with return on assets and cash flows. One potential reason for this negative association between extraversion and CEO performance is the stubbornness of extraverted executives. Extraverted CEOs are more likely to overestimate their own abilities (Hogan and Hogan 2001). They also are less likely to solicit input from coworkers. Extraverts are also known to have a short attention span for projects and ideas (Beaudecel, Brocke, and Leue 2006). Beaudecel et al. (2006) suggest that extraverted executives often make quick decisions to pursue acquisitions and investments. If these investments do not pan out, they are quick to change their game plan, as supported by Gow et al.'s (2016) result of a negative association between extraversion and return on assets.

This tension leads us to state our first hypothesis in the null:

H1: An analyst's level of extraversion is unrelated to their job performance and forecast characteristics. 


\section{Career outcomes}

Green et al. (2018) find support for the relation between extraversion and CEO performance. Specifically, the authors examine extraverted CEOs and CFOs and find that extraverted executives earn statistically higher salaries compared to introverted executives. They also find that extraverted CFOs are more likely to move to the position of CEO. Lastly, being extraverted benefits an executive's career, as they become a top executive at a younger age. On the other hand, Gow et al. (2016) show that extraverted CEOs are associated with worse performance.

The stubbornness and lack of self-awareness of extraverts could have serious implications for an analyst's career. Barber and Odean (2001) demonstrate that overconfidence is a significant factor in investment decisions. They find that males trade $45 \%$ more than females. They credit this difference due to the overconfidence of males. Kumar (2010) finds a similar result in equity analysts. He finds that males are more likely to issue bold forecasts. An overconfident analyst could be less likely to revise a stock recommendation or earnings forecast.

The psychology literature has shown that extraverts are more career oriented, so we expect that an extraverted analyst would prefer to work for a larger brokerage house due to the level of status associated with the largest firms.

Finally, catering to institutional clients is the primary determinant of an analyst's compensation and career success. Extraverted analysts who are more adept at managing social interactions may also be more likely to excel on the qualitative services that institutional investors increasingly value over quantitative outputs. For example, management access, integrity/professionalism, and accessibility/responsiveness. 
Due to the ambiguity over direction, we also state our second hypothesis in the null:

H2: An analyst's level of extraversion is unrelated to their career outcomes.

Personality similarity within relationships

Brochet et al. (2014) provide evidence that the professional relationship analysts and managers develop has economic impacts. Specifically, they find that analysts are more likely to "follow" a CEO/CFO to a new firm and produce more frequent and accurate forecasts for the firm the CEO/CFO moved from. A long history examining personality similarity exists outside economics. For example, Byrne, Griffitt and Stefaniak (1967) find that attraction toward another individual is stronger for similar personalities. More recently, Cuperman and Ickes (2009) find that similar pairs (i.e. 2 extraverts or 2 introverts) have relatively better initial interactions than dissimilar pairs (i.e. extravert-introvert).

However, the literature on extraversion within relationships is mixed. Lester, Haig and Monello (1989) find that high extraversion in either partner within a marriage was related with lower levels of marital satisfaction. Gattis, Berns, Simpson and Christensen (2004) find that similarity between partners' personalities (including extraversion) showed little to no relation with marital happiness.

Within the analyst-executive relationship, it is possible that an extraverted analyst interacts well with an introverted executive (introverted, on a relative scale), as introverts are much better at listening, while extraverts are better in social situations. It is also possible that two extraverts will communicate effectively as they have similar cognition patterns (Beukeboom et al. 2012). Green et al. (2018) find that extraverted CFOs are more likely to be promoted to CEO within the 
company if the prior CEO also exhibited above average levels of extraversion relative to other CEOs.

Due to the ambiguity over direction, we also state our third hypothesis in the null:

H3: The similarity between an analyst's level of extraversion and the CEO's level of extraversion is unrelated to the analyst's job performance, forecast characteristics, and career outcomes.

\section{DATA AND RESEARCH DESIGN}

\section{Measuring Extraversion Linguistic Inquiry and Word Count}

One of the main problems when determining personality characteristics of an individual is data limitations. Kaplan, Klebanov, and Sorensen (2012) and Kaplan and Sorensen (2017) circumvent this problem by using a unique dataset from ghSMART, a consulting firm that specializes in assessing executive talent. ghSMART performed 4-hour structured interviews with executives, ultimately coming up with ratings for 30 specific characteristics and abilities. Kaplan et al. (2012) conclude that personality characteristics significantly explain CEO performance and success.

Green et al. (2018) and Gow et al. (2016) extract linguistic features from quarterly conference calls to measure the executive's personality score across multiple dimensions. Specifically, they use Linguistic Inquiry and Word Count (LIWC) dictionary to assign a score. We use the same computer-based text analysis tool to determine the extraversion level of the analyst. The LIWC was developed by computer science and psychology researchers with the goal of recognizing the Big Five personality traits from a person's speech pattern. One important characterization of both a person's personality traits and their speech pattern is that they are stable across time (Scherer 2003). This allows researchers to score a personality trait based on their 
speech patterns. Dewaele and Furnham (1999) and Furnham (1990) describe specific linguistic cues that are correlated with extraversion. Dewaele and Furnham (1999) find that the correlation between extraversion and a person's speech pattern is improved as the task complexity increases. This relation is fitting for our study, as stock forecasting is a complex task that requires a high level of mastery.

Following Green et al. (2018) and Gow et al. (2016), we use the trained personality algorithms developed by Mairesse et al. (2007). Specifically, Mairesse et al. (2007) develop an algorithm using models based on Naive Bayes and regression trees. They show that their machine learning algorithm produces high classification accuracy when describing a person's Big Five personality characteristics. ${ }^{1}$

We use Seeking Alpha to obtain earnings call transcripts and extract the spoken language of the analyst from the question and answer section of the conference call. Seeking Alpha provides earning call transcripts from 2004 to present day, among other resources. Each quarter, most public companies host a conference call and invite typically five to ten financial analysts that frequently follow and forecast the company. The call consists of two parts. First, the executives provide a summary of the company's performance and activities during the past quarter and often forwardlooking information. This section of the call is known to be scripted, or at the very least, the executives can prepare the topics they would like to discuss. Second, the executives allow the analysts to ask questions in a question-and-answer session. In this part, the analysts typically ask their questions in a back-and-forth manner. Each analyst takes their turn and may ask follow-ups during their turn.

\footnotetext{
${ }^{1}$ Specifically, we use the WEKA software to run the Naive Bayes algorithm, which uses the LIWC dictionary.
} 
We use Python to pull down the transcripts and parse out the analyst text to calculate our extraversion score. We calculate one score per analyst because extraversion is typically sticky over time (Costa and McCrae 1989; Scherer 2003). Specifically, we calculate an extraversion score for each analyst in every conference call and take the average across scores (mean_extra). Each analyst has one decile rank (decile) for their mean extraversion score across their firm-quarter observations. With only one score per analyst, we only need to connect the analyst extraversion score to the analyst identification number (analys) in the $\mathrm{I} / \mathrm{B} / \mathrm{E} / \mathrm{S}$ detail file and the analyst name (analyst) in the $\mathrm{I} / \mathrm{B} / \mathrm{E} / \mathrm{S}$ recommendation file, connected by the translation file. ${ }^{2}$ To make this connection, we match on analyst last name and brokerage firm. We avoid using analyst first names because Seeking Alpha often displays nicknames but not consistently across time, among firms followed, or among brokerage firm employment. A majority of the analysts are the only analyst in that brokerage firm's employment history with a unique last name, a unique analyst-brokerage pair. We only use this group of analysts to increase our confidence in matching the conference call data to $\mathrm{I} / \mathrm{B} / \mathrm{E} / \mathrm{S}$.

Figure 1, Panel A, shows examples from Mairesse et al. (2007) of extravert and introvert conversational text in which the personality types were assessed through the Big Five questionnaire. Mairesse et al. (2007) developed and validated their algorithm to classify individuals back into the personality types using only text. Panel B shows an example of the conference call text conversations of analysts in our sample rated as higher and lower on our extraversion measure.

\footnotetext{
${ }^{2}$ Analyst codes match exactly in the detail (analys) and recommendation (amaskcd) files, but brokerage firm names require judgment and data manipulation to connect the detail (estimator) and recommendation (estimid) files. Analyst name can be found in the recommendation file (analyst) but brokerage firm names need to be hand collected. Diana Weng updated the translation file in March 2017 to connect the I/B/E/S detail and recommendation files and include brokerage firm names.
} 


\section{Sample Selection}

We extract our data from four sources: Seeking Alpha, I/B/E/S, Compustat, and CRSP. We start our sample selection with 1,229,443 analyst-firm-quarter observations over 2006 to 2016 with value and actual from the I/B/E/S detail file, taking only each analyst's last forecast of a particular firm within the quarter (period between earnings announcements). Table 1 contains our sample selection process.

Approximately $75 \%$ of all analyst-call observations come from the 64 largest brokerage firms. The marginal benefit of the next largest brokerage firm is less than $1 \%$ of all analyst-call observations, so we stopped at 64 brokerage firms. Retaining only these 64 brokerage firms in our I/B/E/S sample leaves us with 519,887 observations. The loss of 57.8\% $(709,556 / 1,229,443)$ of our observations tells us that a substantial portion of earnings forecasts do not have a corresponding conference call, at least not those in Seeking Alpha. After requiring the necessary variables from Compustat and CRSP, we have 509,915 analyst-firm-quarters. Finally, we scale our variables in the regression analyses by peer group; another analyst must forecast the same firm in the same period between earnings announcements for the same fpedats. Requiring that each observation have a peer group and a range of forecasts within the peer group provides us with a final sample size of 405,717 analyst-firm-quarters.

< Insert Table 1 here >

\section{Data and Research Design}

First, we consider variables related to an analyst's job performance and forecast characteristics. Detailed variable definitions are in the Appendix. We begin with earnings forecast 
accuracy $(a c c)$ because it is one of the most widely studied summary outputs. We define is as

$\frac{-\mid \text { value-actual| }}{\text { prc }}$, so that a more positive value of acc denotes a more accurate forecast. We expect a positive relation to the extent that extraverted analysts have superior information acquisition skills. We also include the directional measure of forecast error $\left(f \_e r r\right)$ to examine the potential bias in extraverted analyst forecasts and defined as (value-actual)/prc.

We measure boldness as |value - consensus| (Hilary and Hsu 2013) to capture if extraverted analysts are more likely to issue forecasts that deviate from the consensus. We measure the informativeness (inform) of the earnings forecast as the 2-day abnormal returns around the forecast date (excluding those forecasts overlapping with the firm's earnings announcement date) (e.g. Bonner, Hugon and Walther 2007). We measure the level of the recommendation (rec) from $\mathrm{I} / \mathrm{B} / \mathrm{E} / \mathrm{S}$ and collapsed the $\mathrm{I} / \mathrm{B} / \mathrm{E} / \mathrm{S}$ coding into a 3-level recommendation in which a Buy is 3 , Hold is 2 , and Sell is 1 . We measure the timeliness (timeliness) of the analyst reaction to earnings announcements as the number of days between the prior earnings announcement and the first forecast the analyst issues for that firm (Zhang 2008).

Second, we exploit the conference call transcripts to extract measures related to the communication and relationship between analysts and managers (e.g. Call et al. 2018). We measure whether an analyst who was actively forecasting earnings for the firm participated on the call with an indicator variable (CC_Part) equal to 1 if the analyst appears on the call, and 0 if the analyst was not on the call (but was actively following the firm). We include three measures of analyst engagement conditional on the analyst participating on the call (e.g. Call et al. 2018; Jung, Wong, and Zhang 2018). The first is an indicator variable (CC_FirstQ) equal to one if that analyst asked the first question on the call. Managers are more likely to give first question priority to investors or analysts who they view favorably. The second $\left(C C_{-}\right.$words $)$counts the total words 
spoken by the analyst as part of the Q\&A dialogue with management. And the third (CC_dialogues) counts the number of back-and-forth dialogues between the analyst and management. This captures the number of times a given analyst and management take turns speaking to each other (even though a dialogue may start with "Hello" and end with "thank you."

Third, we explore a number of variables related to whether extraverted analysts are associated with career outcomes. Pleasing institutional clients primarily drives an analyst's compensation and career success. Academic and institutional surveys show that institutional clients more highly value sell-side analysts' qualitative services over quantitative outputs (Brown et al. 2015; II Magazine). For example, management access, integrity/professionalism, and accessibility/responsiveness are highly valued but difficult to measure. Many of these important qualitative aspects of an analyst's job are not easily captured by outcome measures like forecast accuracy and boldness. Broker votes and being recognized as an Institutional Investor All-Star analyst are two composite measures capturing the qualitative aspects of an analysts' job and provide compensation and reputation career benefits (Stickel 1992; Groysberg, Healy and Maber 2011; Rees, Sharp and Twedt 2015). We use institutional investors voting on analysts recognized as members of the All-American Research Team (allstar) as our primary quantitative proxy for the qualitative perceptions of institutional clients.

Prior literature uses I/B/E/S to infer the employment history of the analyst (e.g. Hong, Kubik, and Solomon 2000; Hong and Kubik 2003; Kumar 2010). We follow this literature to construct measure related to the career prospects of the analysts. We measure tenure (tenure) as the number of years the analyst has worked at that brokerage. We measure whether an analyst works for a more prestigious brokerage house (prestige) with an indicator variable equal to 1 if the analyst works in a top 10 brokerage firm, in which we define top 10 as the largest brokerage houses 
in $\mathrm{I} / \mathrm{B} / \mathrm{E} / \mathrm{S}$ by the number of analysts employed in that calendar year. We infer promotions, demotions and firings by the movement of the analyst across years. We use indicator variables to capture whether an analyst moves up to (moveup) or moves down from (movesdown) a top 10 brokerage firm from one quarter to the next. We measure whether an analyst has left the profession by if they stop producing forecasts - the indicator variable last_quarter equals 1 if that quarter is the last an analyst appears within $\mathrm{I} / \mathrm{B} / \mathrm{E} / \mathrm{S}$.

Fourth, we use the Q\&A section of the conference calls to create an extraversion score for executives. Specifically, we follow Green et al. (2018) and calculate an executive extraversion score for each conference call and take the mean of this score across all conference call participation for that executive. We measure whether an executive is extraverted relative to the population of executives with an indicator variable (exec_med_ext) equal to 1 if the executive extraversion is greater than or equal to the median executive extraversion.

We include a number of control variables. Firm-specific experience (firmexp) and general experience (genexp) are the number of quarters that an analyst has covered the firm and the number of quarters an analyst has forecasted in I/B/E/S, respectively. Forecast horizon (horizon) is the number of days between the analyst forecast date and the earnings announcement date. Prior forecast accuracy (prioracc) is the analyst's accuracy for that firm in the prior period. Forecast frequency (freq) is the number of earnings forecasts an analyst issues for that firm-quarter. We control for the number of firms (firmscov) and industries (indscov) that an analyst covered in that quarter. We include broker size (bsize) as the number of other analysts forecasting for that brokerage during the quarter. Lastly, we control for the other "Big Five" personality characteristics extracted and coded in the same manner as extraversion. Specifically, we measure the mean 
Openness, Agreeableness, Conscientiousness, and Emotional Stability (i.e. opposite of neuroticism) of an analyst over all conference call participation.

In our analyses, we follow prior literature to control for firm-quarter effects by using a scaled or relative version of the variables (e.g. Clement 1999, Clement and Tse 2005). Specifically, we create a relative transformation based on the range of the variable within a firm-quarter. We subtract the minimum value from the observation value and then divide by the value range. For an example using firm-specific experience (firmexp), analyst A has 11 quarters of experience. Within that firm-quarter for the observation of interest, the minimum experience is 2 and the maximum experience is 20 . Analyst A has an $r_{-}$firmexp of $0.5[(11-2) /(20-2)]$ for the observation in our example. This helps control for firm-quarter specific effects and the differences across firms as analysts may cover different types of firms.

Table 2 presents the descriptive statistics for selected variables in our regression analyses. We focus our discussion on the interquartile range to discuss the behavior of our sample. The mean for mean_extra is 4.718. Interestingly, analyst extraversion is greater than executive extraversion. Green et al. (2018) show that CEOs have an extraversion score of 4.15 and CFOs a score of 3.61. The interquartile range of mean_extra of 4.635 to 4.805 shows that a significant portion of analysts have similar extraversion scores. Similarly, the interquartile range of acc is -0.006 to -0.001 . Consistent with prior literature, analyst recommendations tend to be skewed toward Buys (mean 2.356). Analysts participate on $30 \%$ of the conference calls for firms they are covering. On the conference calls they participate on, analysts have about 3-4 dialogues with management in which they say 170 words on average. Firm experience presents greater variation across the interquartile range, from 6 quarters of experience covering a specific firm to 26 quarters. The variation in firm experience shows us that we have both experienced and greener analysts in our sample. 
Approximately $7.5 \%$ of analysts in our sample have been chosen as Institutional Investor All-Stars for that year. The average analysts in our sample worked for a brokerage employing 51 other analysts, followed about 16 firms across 3 industries during a quarter and produced 26 forecasts for all these firms during the quarter. Forecast horizon ranges from 90 to 301 days in the interquartile range.

\section{< Insert Table 2 here >}

We present correlations between pairs of our variables in Table 3. While most of the pairs have significance at the 5\% level or less, almost none of the pairs have a large correlation coefficient. The only pair with a sufficiently large correlation coefficient is $r_{-}$freq and $r_{-}$firmscov, with a Pearson (Spearman) correlation coefficient of 0.703 (0.726). A majority of the pairs have an absolute value of correlation coefficient less than 0.05 . We are not concerned about multicollinearity in our analysis.

$<$ Insert Table 3 here >

\section{DO EXTRAVERTED ANALYSTS ISSUE DIFFERENT TYPES OF FORECASTS}

We first examine the relationship between extraversion and forecast characteristics within the multivariate setting by testing Equation (1), in which we regress forecast characteristic variables on extraversion and our control variables. We use the relative decile rank ( $r_{-}$decile) as the dependent variable, and the relative versions of the control variables to focus on variation across analysts within a firm-quarter.

$$
r_{-} v a r=\beta_{0}+\beta_{1} r_{-} \text {decile }+ \text { Controls }+\varepsilon
$$

The dependent variable $r_{-}$var represents the forecast characteristic variables related to forecast error $\left(r_{-} f e\right), \quad$ accuracy $\left(r_{-} a c c\right)$, informativeness (r_inform), boldness (r_boldness), 
recommendation level ( $\left.r_{-} r e c\right)$, and timeliness ( $r_{-}$timeliness). We predict that $\beta_{1}$ is significant but we make no predictions on direction. We include year-quarter fixed-effects and cluster standard errors by firm.

We present our regression results in Table 4. Column (1) shows a statistically significant negative relationship between forecast error and extraversion (coef. $-0.003, p$-value $=0.01$ ). This implies that extraverts are more likely to issue a pessimistic earnings forecast with their last forecast before the earnings announcement. This result could reflect an extraverted analyst being more sensitive to managing relationships with executives as a more pessimistic forecast is easier for a manager to meet or beat. Column (2) also provides evidence that extraverts have lower forecast accuracy (coef: $-0.004, p$-value $<0.01$ ). This result implies extraversion has a similar relative size relationship with forecast accuracy as does general experience.

The control variables generally align with expectations. For example, greater general forecasting experience, and accuracy in the prior firm-quarter are positively related with forecast accuracy this period. Horizon is strongly negatively related with forecast accuracy as the farther a forecast is from the subsequent earnings announcement, the more difficult the earnings are to forecast. A greater number of industries covered (inconsistent with expectations) and brokerage size are associated with a higher level of forecast accuracy.

\section{< Insert Table 4 here >}

Column (4) shows that extraverted analysts are positively associated with issuing bold forecasts that move away from the consensus. While we do not make a directional hypothesis, this is consistent with expectations based on the prior psychology literature that shows extraverts are more likely to act in bold and aggressive ways. In addition, Column (6) shows that extraverted analysts are negatively related with the inverse measure of issuing a timely forecast after the 
earnings announcement date; i.e., they are quick to forecast after the firm announces earnings. This is in line with the Beaudecel et al. (2006) finding that extraverted executives are quick to change acquisition and investment decisions. Extraverted analysts appear more likely to quickly issue a forecast following an earnings announcement relative to less extraverted analysts.

Columns (3) and (5) show no specific relation between analyst extraversion and either the market reaction around the analyst's report ( $r_{-}$inform) or the recommendation level on the firm $\left(r_{-} r e c\right)$.

We next examine the relationship between extraversion and conference call characteristics in Table 5. Column (1) shows a statistically significant negative relationship between conference call participation and extraversion (coef. $-0.102, p$-value $<0.01$ ). This implies that extraverts are less likely to participate on a firm's conference call for which they are actively issuing earnings forecasts. Managers tend to give first call priority to investors or analysts with whom they have a close relationship (Call et al. 2018). While Column (2) shows that extraverted analysts are more likely to ask the first question on a conference call, Columns (3) and (4) show that extraverted analysts tend to have less back-and-forth dialogues with management and say less words overall during the Q\&A portion. This finding appears counterintuitive versus psychologists' characterization of extraverts as talkative, energetic people who thrive on social stimuli (Costa and McCrae 1992; Bono and Judge 2004) but may suggest extraverted analysts are less prepared for the conference call and the opportunity for follow-up questions.

Overall, these findings are suggestive of a relation between an analyst's level of extraversion and forecast characteristics, implying that personality traits of analysts relate to their job performance. Despite prior literature showing a relationship between extraversion and positive performance outcomes in executives (e.g. Green et al. 2018), extraversion in the analyst setting 
appears to be related to poorer performance in terms of earnings forecast accuracy and the timeliness of forecast revision following earnings announcements, and a lower level of engagement in public conference calls with management.

\section{EXTRAVERTED ANALYSTS AND THE LABOR MARKET}

We next examine the relation between extraversion and labor market success within the multivariate setting by testing Equation (2), in which we regress career outcomes on extraversion and our control variables. We use the relative decile rank ( $r_{-}$decile) as the dependent variable, and the relative versions of the control variables to focus on variation across analysts within a firmquarter.

$$
\text { career }=\beta_{0}+\beta_{1} r \_ \text {decile }+ \text { Controls }+\varepsilon
$$

The dependent variable career represents the career outcome variables related to being an Institutional Investor All-Star (allstar), time spent at the brokerage ( $r_{-}$tenure), belonging to a prestigious brokerage (prestige), moving up to or down from a prestigious brokerage (moveup or movedown), and leaving the sell-side analyst profession (last_quarter). We predict that $\beta_{1}$ is significant but we make no predictions on direction. We include year-quarter fixed-effects and cluster standard errors by firm.

We present our regression results in Table 6. Column (1) shows a statistically significant negative relationship between being named an Institutional Investor All-Star and extraversion (coef. -0.032, $p$-value $<0.01$ ). This variable is our main summary measure capturing the qualitative aspects of an analysts' job and career success. Practitioner and academic surveys cite that pleasing institutional clients is the primary driver of compensation and career success for a sell-side analyst (Stickel 1992; Groysberg et al. 2011; Brown et al. 2015). While broker votes may have the most 
direct influence on an analyst's compensation, II All-Star recognition based on institutional investor voting is the best public proxy available for the private broker voting.

The career outcomes based on analyst movement within I/B/E/S suggest evidence that runs counter to the enhanced career expectations for extraverts in the executive literature. Specifically, extraverted analysts appear to have shorter tenures at their existing brokerage (Column 2), less likely to work for a prestigious brokerage (Column 3), and less likely to move up to a prestigious brokerage (Column 4). One possibility for this set of results is that despite extraversion being a valued leadership trait in the executive literature, the analyst setting values a separate set of traits on the margin. The lower levels of performance in Table 4 and conference call engagement in Table 5 are consistent with worse career expectations in Table 6 with analysts both less likely to be an II All-Star and have a less prestigious career path.

< Insert Table 6 here >

\section{PERSONALITY SIMILARITY BETWEEN ANALYSTS AND MANAGERS}

Lastly, we examine how the personality similarity between an analyst and the CEO relates to the forecast characteristics and career outcomes of the analyst. Specifically, we test the interaction between an extraverted (introverted) analyst and an extraverted (introverted) CEO by testing Equations (3) and (4). We add to Equations (1) and (2) an indicator variable (exec_med_ext) equal to 1 if the CEO is in the top half of CEOs based on extraversion and interact this with our analyst measure of extraversion $\left(r \_\right.$decile $)$.

$$
\begin{aligned}
& r \_v a r=\beta_{0}+\beta_{1} r \_d e c i l e+\beta_{2} r \_d e c i l e^{*} \text { exec_med_ext }+\beta_{3} \text { exec_med_ext }+ \text { Controls }+\varepsilon \\
& \text { career }=\beta_{0}+\beta_{1} r \_d e c i l e+\beta_{2} r \text { decile*exec_med_ext }+\beta_{3} \text { exec_med_ext }+ \text { Controls }+\varepsilon
\end{aligned}
$$

We predict that $\beta_{3}$ is significant but we make no predictions on direction. We include year-quarter fixed-effects and cluster standard errors by firm. 
We present our regression results in Table 7 with Panel A related to Table 4, Panel B to Table 5, and Panel 6 to Table 6. Despite the psychology literature on personality similarity/dissimilarity and Brochet et al. (2014) providing evidence of a relationship between analysts and managers, we find no personality interaction effects in the relationship between analysts and CEOs of the firm they cover. This lack of evidence contrasts with Green et al. (2018) who find that an extraverted CFO is more likely to be promoted to CEO if the outgoing CEO was also extraverted. Overall, this lack of evidence suggests that similarity between analyst and managers' personalities may not be closely related to analyst forecast characteristics or career outcomes. A strong caveat is that a stronger test may be needed before making conclusions of no effect.

$$
<\text { Insert Table } 7 \text { here > }
$$

\section{ADDITIONAL ANALYSES}

We have reproduced the analysis using the relative raw analyst extraversion score $\left(r_{-}\right.$extra $)$ within firm-quarter instead of $r_{-} d e c i l e$. The results are similar to those presented. Additionally, we create more detailed variables for the personality similarity analysis. Specifically, we define the indicator variables an_int and an_ext to equal 1 if the analyst is in the bottom (introvert) and top (extravert) tercile of our analyst extraversion measure. We define similar indicator variables (exec_int and exec_ext) for executives. This allows us to more finely break out personality interactions across similar personalities (extravert \& extravert versus introvert \& introvert) as well as dissimilar personalities. Results (or more accurately... the no results) are unchanged. 


\section{CONCLUSION}

The ability of sell-side analysts to communicate effectively is critical to their careers. Analysts publically interact with management, during analyst investor days and quarterly earnings calls. Analysts also rely on private communication with management and their relationship with management is highly valued by institutional investors (Brown et al. 2014, 2015). Analysts who are more adept at social interaction could have an advantage, as management may be more willing to speak privately with them. Extraverted analysts' communication style could also help the analyst when they interact with buy-side managers and analysts. Despite prior literature finding extraversion is associated with positive performance and career outcomes in the executive setting, we find that extraverted analysts are associated with less accurate forecasts, less conference call engagement, are less likely to be recognized by institutional investors as All-Stars, and have a less prestigious career path. 


\section{References}

Barber, B. and T Odean. 2001. Boys will be boys: Gender, overconfidence, and common stock investment. The Quarterly Journal of Economics 116(1): 261-292

Beauducel, A., B. Brocke, and A. Leue. 2006. Energetical bases of extraversion: effort, arousal, EEG, and performance. International Journal of Psychophysiology 62(2): 212-23.

Beukeboom, C., M. Tanis, and I. Vermeulen. 2012. The Language of Extraversion: Extraverted People Talk More Abstractly, Introverts Are More Concrete. Journal of Language and Social Psychology 32(2): 191-201.

Block, J. 1995. A contrarian view of the five-factor approach to personality description. Psychological Bulletin 117: 187-215.

Bonner, S., A. Hugon, and B. Walther. 2007. Investor reaction to celebrity analysts: the case of earnings forecast revisions. Journal of Accounting Research 45(3).

Bono, J. E. and T. A. Judge. 2004. Personality and Transformational and Transactional Leadership: A Meta-Analysis. Journal of Applied Psychology 89(5), 901-910.

Bradshaw, M., 2004. How do analysts use their earnings forecasts in generating stock recommendations? The Accounting Review. 79, 25-50.

Bradshaw, M. 2011. Analysts' forecasts: what do we know after decades of work? Working paper.

Bradshaw, M., Y. Ertimur, and P. O’Brien. 2017. Financial analysts and their contribution to wellfunctioning capital markets. Working paper.

Brochet, F., Miller, G., and S. Srinivasas. 2014. Do analysts follow managers who switch companies? An analysis of relationships in the capital markets. The Accounting Review 89(2): 451-482.

Brown, L. D., A. C. Call, M. B. Clement, and N. Y. Sharp. 2015, Inside the "Black Box" of Sell-Side Financial Analysts. Journal of Accounting Research 53: 1-47.

Brown, L. D., A. C. Call, M. B. Clement, and N. Y. Sharp. 2016. The activities of buy-side analysts and the determinants of their stock recommendations. Journal of Accounting and Economics 62: 139156.

Byrne, D., Griffitt, W., and D. Stefaniak, D. 1967. Attraction and similarity of personality characteristics. Journal of Personality and Social Psychology 5(1): 82-90.

Cain, S. 2012. Quiet: The Power of Introverts in a World that Can't Stop Talking. Crown Publishers, New York.

Call, A., N. Sharp, and T. Shohfi. 2018. Which buy-side institutions participate in public earnings conference calls? Implications for capital markets and sell-side coverage. Working paper.

Clement, M. B. 1999. Analyst forecast accuracy: Do ability, resources, and portfolio complexity matter? Journal of Accounting and Economics 27: 285-303. 
Clement, M., \& Tse, S.Y. (2005). Financial analyst characteristics and herding behavior in forecasting. The Journal of Finance, 60, 307-341.

Costa, P. T. and R. R. McCrae. 1989. Rotation to maximize the construct validity of factors in the NEO personality inventory. Multivariate Behavioral Research 24: 107-124.

Costa, P. T. and R. R. McCrae. 1992. Revised NEO Personality Inventory (NEO-PI-R) and NEO Five Factor (NEO-FFI) Inventory Professional Manual. Odessa, FL: PAR.

Cuperman, R., and W. Ickes. 2009. Big Five predictors of behavior and perceptions in initial dyadic interactions: Personality similarity helps extraverts and introverts, but hurts "disagreeables". Journal of Personality and Social Psychology 97(4): 667-684.

Dewaele, J.-M. and A. Furnham. 1999. Extraversion: the unloved variable in applied linguistic research. Language Learning 49(3): 509-544.

Drake, M., P. Joos., J. Pacelli., and B. Twedt. 2019. Analyst forecast bundling. Management Science forthcoming.

Feist, G. J. 1998. A meta-analysis of the impact of personality on scientific and artistic creativity. Personality and Social Psychological Review 2: 290-309.

Furnham, A. 1990. Language and personality. In Giles, H., \& Robinson, W. (Eds.), Handbook of Language and Social Psychology. Winley.

Gattis, K. S., Berns, S., Simpson, L. E., and A. Christensen. 2004. Birds of a Feather or Strange Birds? Ties Among Personality Dimensions, Similarity, and Marital Quality. Journal of Family Psychology, 18(4): 564-574.

Gow, I. D., S. N. Kaplan, D. F. Larcker, and A. A. Zakolyukina. 2016 Working Paper. CEO Personality and Firm Policies.

Green, C, R. Jame, S. Markov, and M. Subasi. 2014. Broker-hosted investor conference. Journal of Accounting and Economics 58(1): 142-166.

Green, C., R. Jame, and B. Lock. 2018 forthcoming. Executive Extraversion: Career and Firm Outcomes. The Accounting Review.

Groysberg,B., P. Healy, and D. Maber. "What Drives Sell-Side Analyst Compensation at High-Status Investment Banks?” Journal of Accounting Research. 49 (2011): 969-1000.

Ham, C., N. Seybert, and S. Wang. 2018. Narcissism is a bad sign: CEO signature size, investment, and performance. Review of Accounting Studies 23(1): 234-264.

Hilary, G. and C. Hsu. 2013. Analyst forecast consistency. Journal of Finance 68(1).

Hogan, R. and Hogan, J. 2001. Assessing Leadership: A View from the Dark Side. International Journal of Selection and Assessment, 9: 40-51.

Hong H, Kubik JD, Solomon A 2000. Security analysts' career concerns and herding of earnings forecasts. Rand Journal of Economics. 31(1):121-144. 
Kubik, Jeffrey D. and Hong, Harrison G. 2003, Analyzing the Analysts: Career Concerns and Biased Earnings Forecasts. The Journal of Finance, Vol. 58, No. 1, pp. 313-351.

Judge, T. A., A. Erez, J. E. Bono, and C. Thoresen. 2002. Discriminant and incremental validity of four personality traits: Are measures of self-esteem, neuroticism, locus of control, and generalized self-efficacy indicators of a common core construct? Journal of Personality and Social Psychology 83: 693-710.

Kaplan, S.N., Klebanov, M.M. Sorensen, M., 2012. Which CEO characteristics and abilities matter? Journal of Finance 67, 973-1007.

Kaplan, Steven Neil and Sørensen, Morten, Are CEOs Different? Characteristics of Top Managers (August 1, 2017). Columbia Business School Research Paper No. 16-27; Paris December 2016 Finance Meeting EUROFIDAI - AFFI. Available at SSRN: $\underline{\text { https://ssrn.com/abstract=2747691 or http://dx.doi.org/10.2139/ssrn.2747691 }}$

Kumar, A. 2010. Self-selection and the forecasting abilities of female equity analysts. Journal of Accounting Research 48(2)

Lester, D., C. Haig, and R. Monello. 1989. Spouses' personality and marital satisfaction. Personality and Individual Differences 10(2): 253-254.

Maber, D., B. Groysberg, and P. Healy. 2014. The use of broker votes to reward brokerage firms' and their analysts' research activities. Working paper.

Mairesse, F., M. A. Walker, M. R. Mehl, and R. K. Moore. 2007. Using linguistic cues for the automatic recognition of personality in conversation and text. Journal of Artificial Intelligence Research 30, 457-500.

Mayew, W. and M. Venkatachalam. 2012. The power of voice: managerial affective states and future firm performance. Journal of Finance 67, 1.

Ones, D. S. S. Dilchert. 2009, How Special Are Executives? How Special Should Executive Selection Be? Observations and Recommendations. Industrial and Organizational Psychology 2: 163-170.

Rees, Lynn, Nathan Sharp, and Brady Twedt. "Who's Heard on the Street? Determinants and Consequences of Financial Analyst Coverage in the Business Press." Review of Accounting Studies 20, no. 1 (March 1, 2015): 173-209

Rustings, C and R. Larsen. 1997. Extraversion, neuroticism, and susceptibility to positive and negative affect: A test of two theoretical models. Person. Individ. Diff. 22(5): 607-612.

Scherer, K. R. 2003. Vocal communication of emotion: A review of research paradigms. Speech Communication 40: 227-256.

Soltes, E. 2014, Private Interaction Between Firm Management and Sell-Side Analysts. Journal of Accounting Research, 52: 245-272.

Stickel, S., 1992. Reputation and performance among security analysts. Journal of Finance 47, 18111836. 
Zhang, Y. 2008. Analyst responsiveness and the post-earnings announcement drift. Journal of Accounting and Economics 46(1): 201-215. 


\title{
Appendix: Variable Definitions
}

\author{
Variable \\ Definition \\ mean_extra \\ $=$ mean extraversion of an analyst over all conference call participation \\ (similar to Green, Jame, and Lock 2018). \\ r_decile \\ $=$ relative decile rank of the analyst extraversion, calculated as (decile - \\ $\min ($ decile $)) /(\max ($ decile $)-\min ($ decile $))$ within a firm-quarter. Unscaled \\ deciles range from 1 to 10 . \\ r_extra \\ $=$ relative raw analyst extraversion score, calculated as (mean_extra - \\ $\min ($ mean_extra $)) /\left(\max \left(m e a n \_e x t r a\right)-\min (\right.$ mean_extra $\left.)\right)$ within a firm- \\ quarter. \\ executive_extra \\ $=$ mean extraversion of an executive over all conference call participation \\ (similar to Green, Lock, and Jame 2018). \\ exec_med_ext \\ $=1$ if executive extraversion greater than or equal to the median executive \\ extraversion (4.890); otherwise, 0.

\section{Forecast Characteristics} \\ $f \_e r r \& r \_f e$ \\ $=$ analyst forecast error, measured as (value - actual) / prc. Relative $f_{-}$err \\ measured as $\left(f \_e r r-\min \left(f \_e r r\right)\right) /\left(\max \left(f \_e r r\right)-\min \left(f \_e r r\right)\right)$ within a firm- \\ quarter. \\ $a c c \& r \_a c c$ \\ $=$ analyst forecast accuracy, measured as $-\mathrm{abs}($ value - actual $) / \mathrm{prc}$. A more \\ positive $a c c$, the better the forecast accuracy. Relative acc measured as (acc - \\ $\min (a c c) /(\max (a c c)-\min (a c c))$ within a firm-quarter. \\ inform \& $r_{-}$inform \\ =2-day abnormal returns around the analyst's forecast. Relative inform \\ measured as (inform - $\min ($ inform $) /(\max ($ inform $)-\min ($ inform $))$ within a \\ firm-quarter. \\ boldness \& r_boldness \\ $=$ absolute value of the distance between analysts forecast and the consensus. \\ Relative boldness measured as (boldness - $\min$ (boldness) / ( $\max ($ boldness) - \\ $\min ($ boldness $)$ ) within a firm-quarter. \\ rec \& $r_{-} r e c$ \\ $=3$ recommendation level for the analyst (buy/hold/sell) in which buy $=3$, \\ hold $=2$, and sell $=1$; recommendation must be since the last earnings \\ announcement for that firm but before or the same day as the analyst's \\ forecast. Relative rec measured as $(r e c-\min (r e c) /(\max (r e c)-\min (r e c))$ \\ within a firm-quarter. \\ timeliness \& $r$ _timeliness \\ $=$ the number of days between the prior earnings announcement and the first \\ quarterly forecast for that analyst for that firm. Relative timeliness measured \\ as (timeliness - $\min ($ timeliness $) /(\max ($ timeliness $)$ - $\min ($ timeliness $))$ within a \\ firm-quarter.
}




\section{Appendix: Variable Definitions (cont.)}

Variable

\section{Conference Call Related CC_Participation}

CC_FirstQ

CC_words

CC_dialogues

\section{Career Outcomes}

allstar

tenure \& r_tenure

prestige

moveup

movedown

last_quarter
Definition

$=1$ if an analyst issued an earnings forecast for that firm in the past 90 days around the conference call and the analyst was on the conference call; otherwise 0 if the analyst issued an earnings forecast in that period but was not on the conference call.

$=1$ if this analyst asked the first question on that call; otherwise 0 for a later question. Only coded for analysts on that call.

$=$ total number of words in Q\&A by an analyst. Only coded for analysts on that call.

$=$ the number of back-and-forth dialogues between each analyst and management, which captures the number of times a given analyst and management take turns speaking to each other (e.g. Jung, Wong, Zhang 2018). Only coded for analysts on that call.

$=1$ for analysts who achieve the Institutional Investor All-America Research Team top three ranking in the following year. Voting occurs for almost the entire month of May, and results are released each October. Therefore, we use the October ranking of a particular year for any forecasts from May of the prior year to April of the observation year. For example, the 2015 rankings applies to May 2014 to April 2015 forecasts.

$=$ number of years the analyst has worked at that brokerage (Kumar 2010). Relative tenure, measured as (tenure - $\min ($ tenure) $)$ / (max(tenure) $\min ($ tenure $)$ ) within a firm-quarter.

$=1$ if analyst works in a top 10 brokerage by number of analysts; otherwise, 0 .

$=1$ if the analyst moves from a non-top 10 brokerage firm to a top 10 brokerage firm by switching brokerage firms; otherwise, 0 .

$=1$ if the analyst moves from a top 10 brokerage firm to a non-top 10 brokerage firm by switching brokerage firms; otherwise, 0 .

$=1$ if the analyst stops forecasting or leaves $\mathrm{I} / \mathrm{B} / \mathrm{E} / \mathrm{S}$ that quarter (Kumar 2010); otherwise 0 . 


\section{Appendix: Variable Definitions (cont.)}

Variable

\author{
Controls \\ firmexp \& r_firmexp \\ genexp \& $r \_g e n e x p$ \\ horizon \& r_horizon \\ prioracc \& r_prioracc
}

freq \& $r_{-}$freq

firmscov \& $r_{-}$firmscov

indscov \& $r_{-}$indscov

bsize \& $r \_b s i z e$

Personality traits
Definition

$=$ number of quarters an analyst has covered that firm. Relative firmexp calculated as (firmexp - min(firmexp $)) /(\max ($ firmexp $)-\min ($ firmexp $))$ within a firm-quarter.

$=$ number of quarters an analyst has forecasted. Relative gexp calculated as $($ genexp - $\min ($ genexp $)) /(\max ($ genexp $)-\min ($ genexp $))$ within a firm-quarter.

$=$ number of days between the analyst forecast and the earnings announcement. Relative horizon calculated as (horizon - $\min ($ horizon)) / (max(horizon) - $\min ($ horizon $))$ within a firm-quarter.

$=$ analyst's accuracy for that firm in the prior period. Relative prior_acc calculated as (prior_acc - $\min ($ prior_acc $)) /(\max ($ prior_acc $)$ $\min ($ prior_acc)) within a firm-quarter.

$=$ the number of forecasts that analyst made during that calendar quarter. Relative freq calculated as $($ freq - $\min ($ freq $)) /(\max ($ freq $)$ - $\min ($ freq $))$ within a firm-quarter.

$=$ number of firms that an analyst covers that quarter. Relative firmscov calculated as (firmscov - $\min ($ firmscov $)) /(\max ($ firmscov $)$ - $\min ($ firmscov $))$ within a firm-quarter.

$=$ number of industries (FF48) that an analyst covers that quarter. Relative indscov calculated as (indscov - $\min ($ indscov $)) /(\max ($ indscov $)$ $\min ($ indscov)) within a firm-quarter.

$=$ number of other analysts forecasting for that brokerage during the quarter. Relative bsize calculated as (bsize - $\min ($ bsize $)) /(\max ($ bsize $)-\min (b s i z e))$ within a firm-quarter.

= mean Openness, Agreeableness, Conscientiousness and Emotional Stability of the analysts over all conference call participation (using the same technique as for Extraversion). 
Figure 1

Text Examples of Extraversion

\section{Panel A: Extract from Table 3 in Mairesse et al. (2007) for participants rated as extremely introvert and extravert.}

\begin{tabular}{|l|l|}
\hline Introvert & Extravert \\
\hline \hline - Yeah you would do kilograms. Yeah I see & - That's my first yogurt experience here. \\
what you're saying. & Really watery. Why? \\
- On Tuesday I have class. I don't know. & - Damn. New game. \\
- I don't know. A16. Yeah, that is kind of cool. & - Oh. \\
- I don't know. I just can't wait to be with & - That's so rude. That. \\
you and not have to do this every night, & - Yeah, but he, they like each other. \\
you know? & He likes her. \\
- Yeah. You don't know. Is there a bed in & - They are going to end up breaking up \\
there? Well ok just... & and he's going to be like. \\
\hline
\end{tabular}

Panel B: Example text from our conference call data for an analyst interaction rated as high and low extravesion

\section{Josephine Millward (High Extraversion)}

- Hi, guys.

- I'm doing well. How are you Brad, Jay?

- Can you, Brad - can you talk to us about the U.K. recompete, congratulations by the way. What is roughly your annual run rate and how do you see this contracts growing over the next ten years going forward?

- Okay. What about - can you talk - can you extend on investment you are making in data link and cyber. You're seen very excited about the future of ISR, are we gaining traction on data link? When can we see it start to contribute?

- Great. Thank you.

\section{Joan Payson (Low Extraversion)}

- Could you speak a little bit to the margin profile of the Asian and e-commerce businesses given they're some of your highest growth segments. And also maybe just what the margin potential is for those longer term versus where they are today? 
TABLE 1

Sample Selection

\section{Analyst-firm-quarters}

$1,229,443$

Analyst-firm-quarters on $\mathrm{I} / \mathrm{B} / \mathrm{E} / \mathrm{S}$ with value and actual using the last analyst forecast per quarter from 2006 to 2016

Require analysts from 64 largest brokerage firms

$(709,556)$

(approximately $75 \%$ of analyst-conference-call observations) to match extraversion scores from conference calls

Require prc from CRSP

513,878

Require a matching gvkey to match with

Compustat

Require a peer group (another analyst must

forecast the same firm in the same period between earnings announcements for the same fpedats)

Require a range (minimum cannot equal the

405,717 relative control measures 
TABLE 2

Descriptive Statistics

Panel A: Descriptive statistics for selected analyst and forecast characteristics

\begin{tabular}{lcccccc}
\hline Variable & $\mathbf{N}$ & Mean & StdDev & P25 & P50 & P75 \\
mean_extra & 405717 & 4.718 & 0.151 & 4.635 & 4.715 & 4.805 \\
f_err & 405717 & 0.003 & 0.025 & -0.002 & 0.000 & 0.002 \\
acc & 405717 & -0.011 & 0.037 & -0.006 & -0.002 & -0.001 \\
inform & 405717 & 0.000 & 0.062 & -0.025 & 0.000 & 0.026 \\
boldness & 365095 & 0.070 & 0.134 & 0.011 & 0.029 & 0.070 \\
rec & 50305 & 2.356 & 0.628 & 2 & 2 & 3 \\
CC_part & 158255 & 0.301 & 0.459 & 0 & 0 & 1 \\
CC_FirstQ & 47701 & 0.139 & 0.346 & 0 & 0 & 0 \\
CC_words & 47701 & 169.238 & 91.416 & 104 & 152 & 215 \\
CC_dialogues & 47701 & 3.832 & 2.371 & 2 & 3 & 5 \\
allstar & 358658 & 0.075 & 0.264 & 0 & 0 & 0 \\
tenure & 384182 & 4.440 & 2.455 & 3 & 4 & 6 \\
firmexp & 405717 & 19.127 & 18.017 & 6 & 14 & 26 \\
genexp & 405717 & 60.915 & 37.416 & 27 & 56 & 95 \\
horizon & 405717 & 213.680 & 169.772 & 90 & 176 & 301 \\
prioracc & 405717 & -0.006 & 0.021 & -0.004 & -0.001 & 0.000 \\
freq & 405717 & 26.330 & 12.939 & 18 & 24 & 32 \\
firmscov & 405717 & 15.893 & 5.794 & 12 & 16 & 19 \\
indscov & 405717 & 3.189 & 1.938 & 2 & 3 & 4 \\
bsize & 405717 & 51.165 & 40.363 & 22 & 37 & 72 \\
\hline & & & & & & \\
\hline & & & & & & \\
\hline
\end{tabular}

(Continued) 
TABLE 2 (continued)

Descriptive Statistics

Panel B: Selected variable means by extraversion terciles

\begin{tabular}{lccc} 
& \multicolumn{3}{c}{ Extraversion Subsets } \\
\cline { 2 - 4 } Variable & Tercile=1 & Tercile=2 & Tercile=3 \\
\hline mean_extra & 4.574 & 4.732 & 4.893 \\
r_decile & 0.157 & 0.493 & 0.827 \\
r_fe & 0.273 & 0.271 & 0.275 \\
r_acc & 0.966 & 0.967 & 0.959 \\
r_inform & 0.529 & 0.529 & 0.530 \\
r_boldness & 0.071 & 0.071 & 0.076 \\
r_rec & 0.674 & 0.680 & 0.682 \\
CC_part & 0.272 & 0.348 & 0.266 \\
CC_FirstQ & 0.116 & 0.150 & 0.147 \\
CC_words & 171.240 & 174.128 & 155.828 \\
CC_dialogue & 3.904 & 3.841 & 3.709 \\
allstar & 0.096 & 0.071 & 0.052 \\
r_tenure & 0.340 & 0.354 & 0.335 \\
r_firmexp & 0.214 & 0.211 & 0.214 \\
r_genexp & 0.507 & 0.459 & 0.445 \\
r_horizon & 0.358 & 0.359 & 0.354 \\
r_prioracc & 0.966 & 0.965 & 0.958 \\
r_freq & 0.348 & 0.337 & 0.344 \\
r_firmscov & 0.482 & 0.483 & 0.474 \\
r_indscov & 0.266 & 0.285 & 0.266 \\
r_bsize & 0.244 & 0.238 & 0.216
\end{tabular}

Panel A presents descriptive statistics for our sample of analyst-firm-quarter observations during 2006 - 2016. Panel $\mathrm{B}$ presents the means of the variables across terciles based on the level of analyst extraversion (mean_extra). See variable definitions in the appendix. Continuous variables are winsorized at $1 \%$ and $99 \%$. 
TABLE 3

Correlations

\begin{tabular}{|c|c|c|c|c|c|c|c|c|c|c|c|}
\hline & r_decile & $r \_a c c$ & $r_{-} f e$ & $r_{-}$firmexp & $r \_g e n e x p$ & r_horizon & r_prioracc & $r_{f}$ freq & r_firmscov & $r_{-}$indscov & r_bsize \\
\hline r_decile & & -0.026 & 0.009 & 0.014 & -0.070 & -0.006 & -0.028 & -0.011 & 0.004 & -0.003 & -0.057 \\
\hline$r \_a c c$ & -0.021 & & -0.593 & 0.009 & 0.040 & -0.050 & 0.641 & -0.034 & -0.009 & 0.031 & 0.020 \\
\hline$r_{-} f e$ & 0.007 & -0.079 & & 0.004 & -0.008 & 0.067 & -0.298 & 0.028 & 0.006 & -0.005 & -0.004 \\
\hline r_firmexp & 0.001 & 0.023 & 0.011 & & 0.276 & 0.032 & 0.017 & 0.107 & 0.204 & 0.136 & 0.061 \\
\hline$r \_$genexp & -0.076 & 0.045 & 0.007 & 0.243 & & 0.038 & 0.045 & 0.133 & 0.206 & 0.047 & 0.092 \\
\hline r_horizon & -0.011 & -0.193 & 0.165 & 0.037 & 0.055 & & 0.015 & 0.033 & 0.024 & -0.003 & -0.022 \\
\hline r_prioracc & -0.028 & 0.445 & 0.022 & 0.029 & 0.046 & 0.026 & & -0.017 & -0.005 & 0.034 & 0.023 \\
\hline$r_{-}$freq & -0.022 & -0.053 & 0.026 & 0.170 & 0.166 & 0.023 & -0.017 & & 0.703 & 0.060 & 0.174 \\
\hline$r_{-}$firmscov & -0.003 & 0.002 & 0.008 & 0.277 & 0.219 & 0.032 & 0.003 & 0.726 & & 0.220 & 0.138 \\
\hline$r_{-}$indscov & -0.003 & 0.037 & 0.012 & 0.147 & 0.041 & 0.018 & 0.031 & 0.061 & 0.198 & & -0.027 \\
\hline$r \_b s i z e$ & -0.062 & 0.030 & 0.000 & 0.104 & 0.112 & 0.012 & 0.030 & 0.203 & 0.169 & -0.039 & \\
\hline allstar & -0.049 & 0.019 & -0.007 & 0.043 & 0.200 & -0.022 & 0.017 & 0.126 & 0.100 & 0.039 & 0.293 \\
\hline
\end{tabular}

This table presents Pearson correlation coefficients above the diagonal, and Spearman correlation coefficients below the diagonal. Bold coefficients indicate significance at the 5\% level or less. See variable definitions in the Appendix. 
TABLE 4

Regression Analyses - Forecast Characteristics

\begin{tabular}{|c|c|c|c|c|c|c|}
\hline VARIABLES & $\begin{array}{c}(1) \\
r \_f e\end{array}$ & $\begin{array}{c}(2) \\
r \_a c c\end{array}$ & $\begin{array}{c}(3) \\
r \_i n f o r m\end{array}$ & $\begin{array}{c}(4) \\
r \_b o l d n e s s\end{array}$ & $\begin{array}{c}(5) \\
r \_r e c\end{array}$ & $\begin{array}{c}(6) \\
r \_t i m e l i n e s s\end{array}$ \\
\hline r_decile & $\begin{array}{c}-0.003 * * \\
(-2.51)\end{array}$ & $\begin{array}{c}-0.004 * * * \\
(-3.31)\end{array}$ & $\begin{array}{l}-0.000 \\
(-0.19)\end{array}$ & $\begin{array}{c}0.011 * * * \\
(3.17)\end{array}$ & $\begin{array}{l}0.012 \\
(1.33)\end{array}$ & $\begin{array}{c}-0.015 * * * \\
(-3.42)\end{array}$ \\
\hline r_firmexp & $\begin{array}{l}0.000 \\
(0.24)\end{array}$ & $\begin{array}{l}-0.001 \\
(-0.93)\end{array}$ & $\begin{array}{l}0.002 \\
(1.18)\end{array}$ & $\begin{array}{c}0.006 * * \\
(2.09)\end{array}$ & $\begin{array}{l}-0.012 \\
(-1.31)\end{array}$ & $\begin{array}{c}-0.019 * * * \\
(-5.40)\end{array}$ \\
\hline$r \_$_genexp & $\begin{array}{l}0.001 \\
(1.26)\end{array}$ & $\begin{array}{c}0.005^{* * *} \\
(5.59)\end{array}$ & $\begin{array}{l}0.001 \\
(0.79)\end{array}$ & $\begin{array}{l}-0.001 \\
(-0.69)\end{array}$ & $\begin{array}{l}0.005 \\
(0.78)\end{array}$ & $\begin{array}{c}0.033 * * * \\
(12.87)\end{array}$ \\
\hline r_horizon & $\begin{array}{c}0.035^{* * * *} \\
(18.85)\end{array}$ & $\begin{array}{c}-0.033 * * * \\
(-18.56)\end{array}$ & $\begin{array}{c}0.011 * * * \\
(7.00)\end{array}$ & $\begin{array}{c}0.024 * * * \\
(7.79)\end{array}$ & $\begin{array}{c}0.041^{* * * *} \\
(5.29)\end{array}$ & $\begin{array}{c}0.116^{* * * *} \\
(29.80)\end{array}$ \\
\hline r_prioracc & $\begin{array}{c}-0.239 * * * \\
(-17.96)\end{array}$ & $\begin{array}{c}0.632 * * * \\
(42.02)\end{array}$ & $\begin{array}{c}0.037 * * * \\
(8.68)\end{array}$ & $\begin{array}{c}-0.496 * * * \\
(-22.24)\end{array}$ & $\begin{array}{c}0.169 * * * \\
(10.93)\end{array}$ & $\begin{array}{c}0.031^{* * * *} \\
(5.92)\end{array}$ \\
\hline$r_{-}$freq & $\begin{array}{c}0.021 * * * \\
(7.47)\end{array}$ & $\begin{array}{c}-0.024 * * * \\
(-6.89)\end{array}$ & $\begin{array}{l}-0.001 \\
(-0.25)\end{array}$ & $\begin{array}{c}0.069 * * * \\
(8.33)\end{array}$ & $\begin{array}{c}-0.059 * * * \\
(-4.22)\end{array}$ & $\begin{array}{c}0.025^{* * *} * \\
(3.49)\end{array}$ \\
\hline$r_{-}$firmscov & $\begin{array}{c}-0.009 * * * \\
(-4.00)\end{array}$ & $\begin{array}{c}0.005^{*} \\
(1.93)\end{array}$ & $\begin{array}{c}-0.005^{* *} \\
(-2.23)\end{array}$ & $\begin{array}{c}-0.028 * * * \\
(-5.24)\end{array}$ & $\begin{array}{l}-0.007 \\
(-0.53)\end{array}$ & $\begin{array}{l}0.010 \\
(1.43)\end{array}$ \\
\hline r_indscov & $\begin{array}{c}0.003^{*} \\
(1.89)\end{array}$ & $\begin{array}{c}0.004 * * \\
(2.22)\end{array}$ & $\begin{array}{l}0.001 \\
(0.49)\end{array}$ & $\begin{array}{c}-0.008 * * \\
(-2.00)\end{array}$ & $\begin{array}{l}0.004 \\
(0.42)\end{array}$ & $\begin{array}{c}-0.024 * * * \\
(-5.45)\end{array}$ \\
\hline r_bsize & $\begin{array}{l}-0.000 \\
(-0.21)\end{array}$ & $\begin{array}{c}0.005^{* * *} \\
(4.40)\end{array}$ & $\begin{array}{c}0.004^{* * *} * \\
(3.29)\end{array}$ & $\begin{array}{c}0.009 * * * \\
(3.93)\end{array}$ & $\begin{array}{c}-0.075^{* * *} \\
(-7.48)\end{array}$ & $\begin{array}{c}0.034 * * * \\
(7.53)\end{array}$ \\
\hline r_openn & $\begin{array}{l}0.001 \\
(0.72)\end{array}$ & $\begin{array}{l}-0.001 \\
(-1.21)\end{array}$ & $\begin{array}{l}0.000 \\
(0.06)\end{array}$ & $\begin{array}{c}0.007 * * * \\
(2.80)\end{array}$ & $\begin{array}{c}-0.014^{*} \\
(-1.87)\end{array}$ & $\begin{array}{c}0.019 * * * \\
(6.28)\end{array}$ \\
\hline r_agree & $\begin{array}{c}0.004^{* * *} * \\
(3.02)\end{array}$ & $\begin{array}{c}0.002 * \\
(1.70)\end{array}$ & $\begin{array}{l}0.001 \\
(0.63)\end{array}$ & $\begin{array}{c}-0.007 * * \\
(-2.09)\end{array}$ & $\begin{array}{l}-0.005 \\
(-0.60)\end{array}$ & $\begin{array}{c}0.018 * * * \\
(4.31)\end{array}$ \\
\hline r_consc & $\begin{array}{c}0.005^{* * *} * \\
(4.08)\end{array}$ & $\begin{array}{l}-0.001 \\
(-0.61)\end{array}$ & $\begin{array}{l}0.000 \\
(0.17)\end{array}$ & $\begin{array}{c}-0.011 * * * \\
(-3.73)\end{array}$ & $\begin{array}{l}0.008 \\
(0.97)\end{array}$ & $\begin{array}{l}0.002 \\
(0.60)\end{array}$ \\
\hline$r_{-} e m o t i$ & $\begin{array}{l}-0.001 \\
(-1.02)\end{array}$ & $\begin{array}{l}-0.001 \\
(-0.97)\end{array}$ & $\begin{array}{l}-0.000 \\
(-0.14)\end{array}$ & $\begin{array}{c}0.009 * * * \\
(3.56)\end{array}$ & $\begin{array}{c}-0.013 * \\
(-1.68)\end{array}$ & $\begin{array}{c}0.008 * * \\
(2.28)\end{array}$ \\
\hline Year-Quarter FE & Yes & Yes & Yes & Yes & Yes & Yes \\
\hline Clustering & Firm & Firm & Firm & Firm & Firm & Firm \\
\hline Observations & 405,717 & 405,717 & 405,717 & 365,095 & 50,304 & 405,717 \\
\hline Adj. R-squared & 0.108 & 0.423 & 0.00229 & 0.195 & 0.0146 & 0.0163 \\
\hline
\end{tabular}

This table presents the results of OLS regressions using firm-quarter analyst observations, with standard errors robust to heteroscedasticity and clustered by firm. r_decile is the relative rank of the analyst extraversion score within firmquarter. Relative variable ("r_variable") are measured as $($ var $-\min (v a r)) /(\max (v a r)-\min (v a r))$ within a firmquarter. See the appendix for variable definitions. Related $t$-statistics are in parentheses. ***, **, and * indicate significance at the $1 \%, 5 \%$, and $10 \%$ levels, respectively. 
TABLE 5

Regression Analyses - Conference Call Characteristics

\begin{tabular}{|c|c|c|c|c|}
\hline VARIABLES & $\begin{array}{c}(1) \\
C C \_p a r t\end{array}$ & $\begin{array}{c}(2) \\
\text { First_Q }\end{array}$ & $\begin{array}{c}(3) \\
r \_C C \_w o r d s\end{array}$ & $\begin{array}{c}(4) \\
r \_C C \_d i a l\end{array}$ \\
\hline r_decile & $\begin{array}{c}-0.102 * * * \\
(-7.32)\end{array}$ & $\begin{array}{c}0.043 * * * \\
(2.67)\end{array}$ & $\begin{array}{c}-0.123 * * * \\
(-12.24)\end{array}$ & $\begin{array}{c}-0.115 * * * \\
(-10.06)\end{array}$ \\
\hline r_firmexp & $\begin{array}{c}0.330 * * * \\
(26.17)\end{array}$ & $\begin{array}{c}0.069 * * * \\
(5.22)\end{array}$ & $\begin{array}{c}0.018 * * \\
(2.42)\end{array}$ & $\begin{array}{c}0.056^{* * *} \\
(6.31)\end{array}$ \\
\hline r_genexp & $\begin{array}{c}-0.215 * * * \\
(-24.44)\end{array}$ & $\begin{array}{c}-0.029 * * * \\
(-2.74)\end{array}$ & $\begin{array}{c}-0.013 * * \\
(-2.16)\end{array}$ & $\begin{array}{l}-0.009 \\
(-1.45)\end{array}$ \\
\hline r_horizon & $\begin{array}{c}0.052 * * * \\
(5.86)\end{array}$ & $\begin{array}{l}0.007 \\
(0.66)\end{array}$ & $\begin{array}{l}-0.009 \\
(-1.41)\end{array}$ & $\begin{array}{l}-0.000 \\
(-0.02)\end{array}$ \\
\hline r_prioracc & $\begin{array}{c}-0.031 * \\
(-1.95)\end{array}$ & $\begin{array}{c}-0.086^{* * *} \\
(-4.38)\end{array}$ & $\begin{array}{c}-0.080 * * * \\
(-5.46)\end{array}$ & $\begin{array}{c}-0.085 * * * \\
(-4.58)\end{array}$ \\
\hline$r_{-}$freq & $\begin{array}{c}-0.129 * * * \\
(-7.02)\end{array}$ & $\begin{array}{l}-0.009 \\
(-0.48)\end{array}$ & $\begin{array}{l}0.018 \\
(1.53)\end{array}$ & $\begin{array}{c}0.060 * * * \\
(4.47)\end{array}$ \\
\hline$r_{-}$firmscov & $\begin{array}{c}0.033^{*} \\
(1.80)\end{array}$ & $\begin{array}{c}0.079 * * * \\
(3.96)\end{array}$ & $\begin{array}{c}-0.032 * * * \\
(-2.80)\end{array}$ & $\begin{array}{c}-0.066 * * * \\
(-5.03)\end{array}$ \\
\hline r_indscov & $\begin{array}{c}0.073 * * * \\
(6.38)\end{array}$ & $\begin{array}{c}0.022 * \\
(1.96)\end{array}$ & $\begin{array}{c}0.017 * * \\
(2.01)\end{array}$ & $\begin{array}{c}0.039 * * * \\
(4.07)\end{array}$ \\
\hline r_bsize & $\begin{array}{c}-0.033 * * \\
(-2.52)\end{array}$ & $\begin{array}{c}0.054 * * * \\
(3.55)\end{array}$ & $\begin{array}{l}-0.002 \\
(-0.17)\end{array}$ & $\begin{array}{c}-0.037 * * * \\
(-4.08)\end{array}$ \\
\hline r_openn & $\begin{array}{c}-0.091 * * * \\
(-8.15)\end{array}$ & $\begin{array}{c}-0.077 * * * \\
(-5.68)\end{array}$ & $\begin{array}{c}-0.233 * * * \\
(-29.17)\end{array}$ & $\begin{array}{c}-0.144 * * * \\
(-16.33)\end{array}$ \\
\hline r_agree & $\begin{array}{c}0.089 * * * \\
(7.42)\end{array}$ & $\begin{array}{c}-0.032 * * \\
(-2.17)\end{array}$ & $\begin{array}{c}-0.025 * * * \\
(-2.67)\end{array}$ & $\begin{array}{c}0.097 * * * \\
(9.55)\end{array}$ \\
\hline$r_{-}$consc & $\begin{array}{c}0.112 * * * \\
(8.18)\end{array}$ & $\begin{array}{c}0.030 * * \\
(2.12)\end{array}$ & $\begin{array}{c}0.070 * * * \\
(8.08)\end{array}$ & $\begin{array}{c}0.030 * * * \\
(3.14)\end{array}$ \\
\hline r_emoti & $\begin{array}{c}-0.076 * * * \\
(-6.22)\end{array}$ & $\begin{array}{c}-0.040 * * * \\
(-2.59)\end{array}$ & $\begin{array}{c}0.025^{* * * *} \\
(2.65)\end{array}$ & $\begin{array}{l}-0.021 * \\
(-1.95)\end{array}$ \\
\hline $\begin{array}{l}\text { Year-Quarter FE } \\
\text { Clustering }\end{array}$ & $\begin{array}{l}\text { Yes } \\
\text { Firm }\end{array}$ & $\begin{array}{l}\text { Yes } \\
\text { Firm }\end{array}$ & $\begin{array}{l}\text { Yes } \\
\text { Firm }\end{array}$ & $\begin{array}{l}\text { Yes } \\
\text { Firm }\end{array}$ \\
\hline Observations & 158,241 & 47,662 & 47,698 & 47,698 \\
\hline ROC & 0.641 & 0.600 & & \\
\hline Adj. R-squared & & & 0.106 & 0.106 \\
\hline
\end{tabular}

This table presents the results of probit (Columns 1 and 2) and OLS regressions (Columns 3 and 4) using firm-quarter

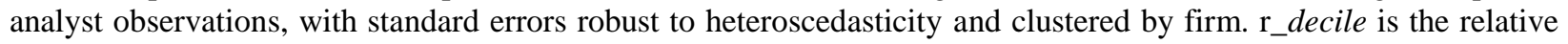
rank of the analyst extraversion score within firm-quarter. Relative variable ("r_variable") are measured as (var $\min (v a r)) /(\max (v a r)-\min (v a r))$ within a firm-quarter. See the appendix for variable definitions. Related $t$-statistics are in parentheses. $* * *, * *$, and $*$ indicate significance at the $1 \%, 5 \%$, and $10 \%$ levels, respectively. 
TABLE 6

Regression Analyses - Career Outcomes

\begin{tabular}{|c|c|c|c|c|c|c|}
\hline VARIABLES & $\begin{array}{c}(1) \\
\text { allstar }\end{array}$ & $\begin{array}{c}(2) \\
r \_t e n u r e\end{array}$ & $\begin{array}{c}(3) \\
\text { prestige }\end{array}$ & $\begin{array}{c}\text { (4) } \\
\text { moveup }\end{array}$ & $\begin{array}{c}(5) \\
\text { movedown }\end{array}$ & $\begin{array}{c}(6) \\
\text { last_quarter }\end{array}$ \\
\hline r_decile & $\begin{array}{c}-0.032 * * * \\
(-4.41)\end{array}$ & $\begin{array}{c}-0.036 * * * \\
(-8.95)\end{array}$ & $\begin{array}{c}-0.028 * * \\
(-2.10)\end{array}$ & $\begin{array}{c}-0.002 * * * \\
(-2.84)\end{array}$ & $\begin{array}{c}-0.003 * * * \\
(-3.30)\end{array}$ & $\begin{array}{c}-0.005 * * * \\
(-3.72)\end{array}$ \\
\hline$r_{-}$firmexp & $\begin{array}{c}-0.026 * * * \\
(-5.35)\end{array}$ & $\begin{array}{c}0.791 * * * \\
(85.57)\end{array}$ & $\begin{array}{c}0.087 * * * \\
(7.52)\end{array}$ & $\begin{array}{c}0.003 * * * \\
(4.56)\end{array}$ & $\begin{array}{c}0.006 * * * \\
(8.07)\end{array}$ & $\begin{array}{c}0.010 * * * \\
(6.59)\end{array}$ \\
\hline$r_{-}$genexp & $\begin{array}{c}0.173 * * * \\
(30.54)\end{array}$ & $\begin{array}{c}-0.030 * * * \\
(-10.45)\end{array}$ & $\begin{array}{c}0.037 * * * \\
(4.12)\end{array}$ & $\begin{array}{c}-0.002 * * * \\
(-4.43)\end{array}$ & $\begin{array}{c}0.004 * * * \\
(6.68)\end{array}$ & $\begin{array}{l}0.001 \\
(1.58)\end{array}$ \\
\hline r_horizon & $\begin{array}{l}0.005 \\
(1.10)\end{array}$ & $\begin{array}{c}-0.049 * * * \\
(-18.95)\end{array}$ & $\begin{array}{l}-0.010 \\
(-1.49)\end{array}$ & $\begin{array}{c}0.001 * * \\
(2.06)\end{array}$ & $\begin{array}{c}0.002 * * * \\
(3.02)\end{array}$ & $\begin{array}{c}0.002 * \\
(1.80)\end{array}$ \\
\hline r_prioracc & $\begin{array}{c}0.020 * * \\
(2.48)\end{array}$ & $\begin{array}{c}-0.010 * * \\
(-2.20)\end{array}$ & $\begin{array}{c}0.041 * * * \\
(3.21)\end{array}$ & $\begin{array}{l}0.001 \\
(0.75)\end{array}$ & $\begin{array}{l}0.002 \\
(1.40)\end{array}$ & $\begin{array}{l}0.001 \\
(0.67)\end{array}$ \\
\hline$r_{-}$freq & $\begin{array}{c}0.113 * * * \\
(14.69)\end{array}$ & $\begin{array}{c}-0.018 * * * \\
(-2.88)\end{array}$ & $\begin{array}{c}0.247 * * * \\
(18.41)\end{array}$ & $\begin{array}{c}-0.007 * * * \\
(-5.65)\end{array}$ & $\begin{array}{c}-0.004 * * \\
(-2.40)\end{array}$ & $\begin{array}{c}-0.038 * * * \\
(-9.89)\end{array}$ \\
\hline$r_{-}$firmscov & $\begin{array}{l}-0.009 \\
(-1.10)\end{array}$ & $\begin{array}{c}0.104 * * * \\
(17.37)\end{array}$ & $\begin{array}{c}-0.073 * * * \\
(-5.32)\end{array}$ & $\begin{array}{l}0.001 \\
(1.04)\end{array}$ & $\begin{array}{c}-0.015^{* * *} \\
(-9.14)\end{array}$ & $\begin{array}{c}-0.035 * * * \\
(-12.63)\end{array}$ \\
\hline r_indscov & $\begin{array}{c}0.036 * * * \\
(5.87)\end{array}$ & $\begin{array}{c}0.039 * * * \\
(10.06)\end{array}$ & $\begin{array}{c}-0.094 * * * \\
(-8.94)\end{array}$ & $\begin{array}{c}-0.003 * * * \\
(-5.28)\end{array}$ & $\begin{array}{c}-0.002 * * * \\
(-3.36)\end{array}$ & $\begin{array}{c}-0.011 * * * \\
(-7.99)\end{array}$ \\
\hline r_boldness & $\begin{array}{l}0.005 \\
(0.75)\end{array}$ & $\begin{array}{c}-0.015 * * * \\
(-3.23)\end{array}$ & $\begin{array}{c}0.030 * * * \\
(2.62)\end{array}$ & $\begin{array}{l}0.001 \\
(0.98)\end{array}$ & $\begin{array}{c}0.005 * * * \\
(5.69)\end{array}$ & $\begin{array}{l}0.002 \\
(0.96)\end{array}$ \\
\hline r_bsize & $\begin{array}{c}0.285 * * * \\
(41.43)\end{array}$ & $\begin{array}{l}0.007 \\
(1.35)\end{array}$ & & & & $\begin{array}{c}0.013 * * * \\
(8.93)\end{array}$ \\
\hline allstar & & $\begin{array}{c}-0.026 * * * \\
(-9.48)\end{array}$ & $\begin{array}{c}0.362 * * * \\
(52.55)\end{array}$ & $\begin{array}{l}-0.001 * \\
(-1.95)\end{array}$ & $\begin{array}{c}-0.004 * * * \\
(-5.65)\end{array}$ & $\begin{array}{c}-0.036 * * * \\
(-14.87)\end{array}$ \\
\hline r_openn & $\begin{array}{c}-0.036 * * * \\
(-5.87)\end{array}$ & $\begin{array}{c}0.008 * * \\
(1.97)\end{array}$ & $\begin{array}{l}0.017 \\
(1.64)\end{array}$ & $\begin{array}{c}0.001 * \\
(1.77)\end{array}$ & $\begin{array}{c}0.002 * * * \\
(3.24)\end{array}$ & $\begin{array}{c}0.009 * * * \\
(7.38)\end{array}$ \\
\hline r_agree & $\begin{array}{c}-0.022 * * * \\
(-3.58)\end{array}$ & $\begin{array}{l}0.002 \\
(0.58)\end{array}$ & $\begin{array}{c}-0.089 * * * \\
(-7.73)\end{array}$ & $\begin{array}{c}0.001 * * \\
(2.06)\end{array}$ & $\begin{array}{l}0.001 \\
(1.21)\end{array}$ & $\begin{array}{c}-0.010 * * * \\
(-7.95)\end{array}$ \\
\hline$r_{-}$consc & $\begin{array}{l}-0.005 \\
(-0.60)\end{array}$ & $\begin{array}{c}0.022 * * * \\
(5.57)\end{array}$ & $\begin{array}{c}0.019 * \\
(1.69)\end{array}$ & $\begin{array}{c}0.001 * \\
(1.91)\end{array}$ & $\begin{array}{l}-0.000 \\
(-0.38)\end{array}$ & $\begin{array}{c}0.009 * * * \\
(6.63)\end{array}$ \\
\hline r_emoti & $\begin{array}{c}0.038 * * * \\
(5.65)\end{array}$ & $\begin{array}{c}0.009 * * \\
(2.20)\end{array}$ & $\begin{array}{l}0.015 \\
(1.27)\end{array}$ & $\begin{array}{l}0.001 \\
(1.14)\end{array}$ & $\begin{array}{c}0.002 * * * \\
(3.13)\end{array}$ & $\begin{array}{c}0.006^{* * * *} \\
(4.46)\end{array}$ \\
\hline Year-Quarter FE & Yes & Yes & Yes & Yes & Yes & Yes \\
\hline Clustering & Firm & Firm & Firm & Firm & Firm & Firm \\
\hline $\begin{array}{l}\text { Observations } \\
\text { Adj. R-squared }\end{array}$ & 320,741 & $\begin{array}{c}320,864 \\
0.601\end{array}$ & 320,857 & 309,215 & 306,924 & 319,130 \\
\hline ROC & 0.868 & & 0.666 & 0.712 & 0.770 & 0.752 \\
\hline
\end{tabular}


This table presents the results of probit regressions for all columns (except OLS for the continuous variable $r$ tenure) using firm-quarter analyst observations, with standard errors robust to heteroscedasticity and clustered by firm. r_decile is the relative rank of the analyst extraversion score within firm-quarter. Relative variable ("r_variable") are measured as $(v a r-\min (v a r)) /(\max (v a r)-\min (v a r))$ within a firm-quarter. See the appendix for variable definitions. Related $z$ - or $t$-statistics are in parentheses. ***,**, and * indicate significance at the $1 \%, 5 \%$, and $10 \%$ levels, respectively. 
TABLE 7

Regression Analyses - Executive-Analyst Personality Similarity

Panel A: Executive-analyst personality similarity \& forecast characteristics

\begin{tabular}{|c|c|c|c|c|c|c|}
\hline VARIABLES & $\begin{array}{l}(1) \\
r_{-} f e\end{array}$ & $\begin{array}{c}(2) \\
r \_a c c\end{array}$ & $\begin{array}{c}(3) \\
r \_ \text {inform }\end{array}$ & $\begin{array}{c}(4) \\
r \_b o l d n e s s\end{array}$ & $\begin{array}{c}(5) \\
r \_r e c\end{array}$ & $\begin{array}{c}(6) \\
r \_t i m e l i n e s s\end{array}$ \\
\hline$r \_$decile & $\begin{array}{l}-0.000 \\
(-0.12)\end{array}$ & $\begin{array}{l}-0.002 \\
(-1.22)\end{array}$ & $\begin{array}{l}0.001 \\
(0.13)\end{array}$ & $\begin{array}{l}0.008 \\
(1.45)\end{array}$ & $\begin{array}{l}-0.018 \\
(-0.97)\end{array}$ & $\begin{array}{c}-0.025 * * * \\
(-3.32)\end{array}$ \\
\hline r_decile* $*$ exec_med_ext & $\begin{array}{l}-0.001 \\
(-0.56)\end{array}$ & $\begin{array}{l}-0.001 \\
(-0.53)\end{array}$ & $\begin{array}{l}0.003 \\
(0.36)\end{array}$ & $\begin{array}{l}-0.002 \\
(-0.36)\end{array}$ & $\begin{array}{l}0.023 \\
(1.15)\end{array}$ & $\begin{array}{l}0.003 \\
(0.41)\end{array}$ \\
\hline exec_med_ext & $\begin{array}{l}0.001 \\
(0.85)\end{array}$ & $\begin{array}{l}-0.000 \\
(-0.02)\end{array}$ & $\begin{array}{l}0.001 \\
(0.23)\end{array}$ & $\begin{array}{l}-0.005^{*} \\
(-1.73)\end{array}$ & $\begin{array}{l}-0.013 \\
(-1.18)\end{array}$ & $\begin{array}{l}0.000 \\
(0.08)\end{array}$ \\
\hline Controls & Yes & Yes & Yes & Yes & Yes & Yes \\
\hline $\begin{array}{l}\text { Observations } \\
\text { Adi R-squared }\end{array}$ & $\begin{array}{c}146,626 \\
00966\end{array}$ & $\begin{array}{c}146,626 \\
0.373\end{array}$ & $\begin{array}{l}146,626 \\
000282\end{array}$ & $\begin{array}{c}137,266 \\
0144\end{array}$ & $\begin{array}{l}17,813 \\
00118\end{array}$ & $\begin{array}{c}146,626 \\
00188\end{array}$ \\
\hline
\end{tabular}

Panel B: Executive-Analyst personality similarity \& conference call characteristics

(1)

VARIABLES

r_decile

r_decile*exec_med_ext

exec_med_ext

Controls

Observations

ROC

Adj. R-squared
(2)

(3)

r_CC_words

$0.047 * *$

(2.52)

0.013

(0.66)

$-0.005$

$(-0.46)$

Yes

44,217

0.600

44,249
(4)

r_CC_dial

$-0.117 * * *$

$(-9.11)$

0.007

$(0.55)$

$-0.013$

$(-1.53)$

Yes

44,249

0.156

0.105 
TABLE 7 (continued)

Regression Analyses - Executive-Analyst Personality Similarity

\section{Panel C: Executive-Analyst Personality Similarity \& Career Outcomes}

(1)

(2)

allstar

VARIABLES

$$
\text { r_decile }
$$

$r \_d e c i l e * e x e c \_m e d \_e x t$

exec_med_ext

Controls

Observations
ROC

Adj. R-squared

$-0.01$

$(-0.89)$

$(1.05)$

110,969
0.858

0.689
(3)

(4)

(5)

(6)

r_tenure prestige

moveup

movedown last_quarter

$-0.024 * * *$

0.012

$-0.003 *$

$-0.001$

$-0.007 * *$

$(-3.41)$

(0.56)

$(-1.96)$

$(-0.90)$

$(-2.25)$

0.003

$-0.031$

0.001

0.000

(0.08)

0.002

(0.43)

$(-1.49)$

(0.45)

0.001

(0.65)

0.002

$0.019 *$

$-0.001$

(0.75)

(1.75)

(0.52)

Yes

$(-1.20)$

Yes

Yes

$-0.003$

Yes

111,136

111,119

102,425

98,507

109,366

0.668

0.738

0.777

0.750

This table presents the results of OLS (Adj. $\mathrm{R}^{2}$ ) and probit (ROC) regressions using firm-quarter analyst observations, with standard errors robust to heteroscedasticity and clustered by firm. The Control variables including Year-Quarter fixed effects are the same as in Tables 4, 5, and 6. r_decile is the relative rank of the analyst extraversion score within firm-quarter. exec_med_ext is an indicator variable equal to 1 if the extraversion of the CEO is greater than or equal to the median CEO extraversion level. Relative variable ("r_variable") are measured as (var - $\min ($ var $)) /(\max (v a r)$ $-\min (v a r)$ ) within a firm-quarter. See the appendix for variable definitions. Related $t$-statistics are in parentheses. $* * *, * *$, and $*$ indicate significance at the $1 \%, 5 \%$, and $10 \%$ levels, respectively. 